\title{
Uso da integração lavoura-pecuária-floresta e proteção de áreas de preservação permanente em propriedades familiares: relato de uma experiência extensionista
}

Use of crop-livestock-forest and protection of permanent preservation areas in smallhoders family farms: report of an extensionist experience

\author{
Marcelo Rodrigues Martins ${ }^{1}$ \\ Marcelo Lacerda Rezende ${ }^{2}$
}

\section{RESUMO}

O presente texto objetiva relatar as experiências de um projeto de extensão ${ }^{3}$ realizado pela Universidade Federal de Alfenas em parceria com a Empresa de Assistência Técnica e Extensão Rural do Estado de Minas Gerais (EMATER-MG), regional de Alfenas, visando implantar e avaliar 12 unidades experimentais em municípios com tradição leiteira da região Sul de Minas Gerais, com o objetivo de adaptar sistemas de integração lavoura-pecuáriafloresta (ILPF) para as realidades locais, recuperando áreas degradadas, intensificando a utilização das pastagens e implementando áreas de proteção em nascentes e/ou vegetação ciliar. Foram realizados 4 dias de campo, com a capacitação de 138 produtores rurais, além da utilização dessas propriedades em cursos em bovinocultura e meio ambiente para produtores e técnicos. Os sistemas ILPF apresentam-se como alternativas viáveis para melhoria da geração de renda e serviços ambientais nas propriedades, respeitando-se as exigências impostas pela legislação ambiental. Dessa forma, o produtor rural e a sociedade são beneficiados com a preservação do meio ambiente. Houve efetiva construção do conhecimento entre agricultores familiares, a comunidade atendida, acadêmicos, docentes e técnicos da EMATER-MG.

Palavras-chave: Agricultura familiar. Extensão rural. Serviços ambientais. Unidades experimentais.

\begin{abstract}
This paper aimed to report the experiences of an extension project conducted by the Federal University of Alfenas in partnership with EMATER-MG regional Alfenas, aiming to implement and evaluate twelve units were deployed in cities with dairy tradition in the South of Minas Gerais, Brazil, in order to adapt the integrated crop-livestock-forest (ILPF) to local realities, with restoring degraded areas, intensifying the use of pastures and implementing protected areas in springs and or riparian vegetation. There were performed four field days, with the training of 138 farmers, besides the use of these properties in courses and environment for cattle producers and technicians. Crop-livestock-forest (ILPF) systems present themselves as viable alternatives for improving income generation and environmental services in the properties, complying with the requirements imposed by environmental legislation. Thus, the smallholders and the society were benefited with the preservation of the

\footnotetext{
1 Mestre em Nutrição Animal pela Universidade Federal de Viçosa, Minas Gerais, Brasil; coordenador técnico na Empresa de Assistência Técnica e Extensão Rural do Estado de Minas Gerais, Sul de Minas Gerais, Brasil (marcelo.martins@emater.mg.gov.br).

${ }^{2}$ Doutor em Economia Aplicada pela Escola Superior de Agricultura Luiz de Queiróz da Universidade de São Paulo, Brasil; estágio pós-doutoral no Department of Agricultural Economics da Texas A\&M University, Estados Unidos; professor associado III da Universidade Federal de Alfenas, Minas Gerais, Brasil (marcelo.1.rezende@gmail.com).

${ }^{3}$ Projeto financiado pela Fundação de Amparo à Pesquisa do Estado de Minas Gerais (FAPEMIG).
} 
environment. Thus, allowing an effective construction of knowledge between the smallholders, the community served, academics, teachers and EMATER-MG.

Keywords: Family farming. Rural extension. Environmental services. Experimental units.

\section{INTRODUÇÃO}

A busca pela sustentabilidade nas atividades agrárias constitui-se num aspecto básico para pensar o desenvolvimento rural na atualidade. Contrapondo o quadro de desequilíbrio e deterioração ambiental existente, há um amplo quadro legal visando à conservação dos recursos naturais. Entretanto, sua efetivação ainda é um desafio e dessa forma, a manutenção dos serviços ambientais existentes fica comprometida, influenciando diretamente na qualidade de vida da população no campo e na produtividade das atividades agropecuárias (SEIDEL; FOLETO, 2009).

Compreender melhor esse contexto socioeconômico e ambiental, dentro e fora dos limites de um estabelecimento rural, pode ser útil no processo de planejamento e condução das atividades agrossilvipastoris, conciliando-as à conservação e ao uso racional dos recursos naturais (FERREIRA et al., 2014)

Em Minas Gerais, a lei estadual 18.365/2009 prevê, em seu Art. 2º que as áreas de preservação permanente, incluindo encostas e morros ocupados com culturas agrícolas anuais e perenes, deverão ser convertidas progressivamente em vegetação nativa de forma compatível com seu uso atual e com sua importância para a manutenção da renda familiar (ALMG, 2010). Entretanto, como afirmaram Seidel e Foleto (2009), a efetivação dessa lei é um desafio, e pelo menos duas grandes questões dificultam seu cumprimento pelos produtores rurais. Em primeiro lugar, muitos desses produtores ainda desconhecem o que está previsto na lei e/ou não possuem o conhecimento técnico para realizar em suas propriedades as mudanças previstas. A própria lei determina que o estado de Minas Gerais, por meio de órgãos competentes, forneça o apoio necessário aos produtores para que possam cumpri-la. Ações do poder público vêm sendo executadas, mas necessitam de maior abrangência.

Além disso, a Lei Florestal federal 12.651/2012 (BRASIL, 2012) criou dois instrumentos importantes para a regularização ambiental das propriedades ou posses rurais: o Cadastro Ambiental Rural (CAR) e o Programa de Recuperação Ambiental (PRA), que tem sua correspondência em Minas Gerais pela Lei Florestal mineira 20.922/2013 (MINAS GERAIS, 2013). A Lei Florestal federal estabeleceu como tarefa da União e dos estados a implantação 
do PRA. Cabe aos estados o detalhamento do programa, que terá por objetivo a regularização ambiental das propriedades e posses rurais.

Outra importante questão está relacionada com o fato de que em muitas propriedades rurais, principalmente as pequenas, as áreas de proteção permanente são ocupadas com culturas agrícolas ou pecuárias e representam uma importante parcela da renda para seus proprietários. Assim, o isolamento e cercamento dessas áreas poderiam causar perdas para os produtores. Entretanto, novas alternativas ou tecnologias podem ser pensadas para compensar essas perdas. Bacha (2005) demonstra em um estudo de caso para a bacia do rio Piracicaba que a recomposição da reserva legal é possível, com pequenos impactos sobre a produção agropecuária, aliadas a melhorias na eficiência do uso do solo nas áreas de produção, com correção e adubação de solos, rotação de culturas, práticas de conservação de água no solo e plantio direto na palha, dentre outras. Outra alternativa está prevista na própria lei sobre as políticas florestal e de proteção à biodiversidade no Estado, Lei 20.922/2013, que para essas áreas de proteção permanente admite a implantação de sistemas agroflorestais, desde que mantenham sua finalidade ambiental. Entretanto, muitos produtores desconhecem como formar e manejar esses sistemas ou, ainda, os benefícios dessa prática. Nesse contexto, podese considerar que sem o necessário apoio técnico e sem alternativas que minimamente compensem a não utilização das áreas de proteção permanente, os produtores rurais dificilmente irão conseguir ou estar dispostos a cumprir o que determina a citada lei.

A região Sul de Minas Gerais, caracterizada por pequenas propriedades, possui na atividade agropecuária um importante segmento socioeconômico, gerador de emprego e renda para grande parte da população ativa. Dentre suas principais atividades estão cafeicultura, olericultura, cultura do milho, bovinocultura leiteira e avicultura de postura. O milho é suficiente para atender a demanda e ser exportado para outras regiões, mas, para suprir a exigência regional em matérias primas, tem ocorrido a importação de soja e produtos florestais de outras regiões (IBGE, 2018). O sistema de plantio de milho e soja direto na palha de braquiária já está consolidado entre os produtores, mas não há uma adequada utilização dessa forrageira como pastagem no período seco subsequente.

Também carece de chegar aos bovinocultores, que ainda utilizam o sistema tradicional de plantio de milho para silagem, com aração e gradagem, a informação de que eles podem utilizar áreas alternadas dentro da fazenda e no sistema de plantio direto na palha. Essa prática pode elevar a capacidade de suporte médio das propriedades, melhorando a produção e produtividade, iniciando produtores ao "cultivo de pastagens" e reduzindo a pressão sobre 
áreas que deveriam estar preservadas, áreas de proteção permanente (APP) e reservas legais (FERREIRA et al., 2014).

Neste sentido, o incentivo à implantação de sistemas sustentáveis de produção, como sistemas de integração lavoura-pecuária e floresta (ILPF), poderá contribuir com o fortalecimento do setor agropecuário regional, tornando-o mais competitivo e integrado a outros segmentos do agronegócio da região. Tal sistema pode, também, reduzir a utilização de áreas de preservação por parte dos agricultores, pois apresenta uma maior eficiência produtiva por combinar três atividades numa mesma área. Esse sistema é uma inovação tecnológica apropriada às condições de diversas propriedades da região Sul de Minas Gerais, o que justifica o esforço da pesquisa, ensino e extensão na adoção dessa iniciativa (PADOVAN; PEZARICO; OTSUBO, 2015).

A implantação de unidades de experimentação (UE) de ILPF e a proteção de nascentes e matas ciliares em córregos fazem parte de uma estratégia dos órgãos envolvidos no desenvolvimento da agropecuária regional. Essa estratégia tem como objetivo viabilizar a melhoria dos índices produtivos das propriedades leiteiras da região por meio da implantação de sistemas agroflorestais sustentáveis.

Assim, o presente trabalho tem como objetivo relatar as atividades de um projeto de extensão que procurou levar, aos produtores rurais, alternativas que permitam a utilização das áreas de proteção permanente, nos limites impostos por lei, e outras que mostrem como, nas áreas restantes, gerar renda igual ou superior a obtida com a utilização indevida dessas áreas.

\section{MATERIAL E MÉTODOS}

A Emater, no sul de Minas Gerais, tem 115 municípios atendidos com escritórios locais, aos quais foi ofertado o programa e selecionados 12 dos que mais se enquadravam na aptidão do técnico e do agricultor familiar, visando à implantação das UE. Essas propriedades tinham entre 8 e 32 ha, utilizavam mão de obra familiar e produção variando de 100 a 250 Litros/dia.

Os 12 municípios selecionados foram: Alterosa, Boa Esperança, Carmo do Rio Claro, Elói Mendes, Córrego Fundo, Cristais, Alpinópolis, Fortaleza de Minas, Pratápolis, Santa Rita de Caldas, Serrania e São João da Mata.

As UE são consideradas um espaço no qual extensionistas e agricultores familiares irão construir ou reconstruir conhecimentos que fundamentaram uma tecnologia ou uma prática 
agropecuária ou social. O objetivo de sua implantação é permitir que seus participantes possam conhecer outras técnicas e avaliar seus resultados econômicos, sociais e ambientais, refletindo sobre suas vantagens quando comparados com as tecnologias utilizadas anteriormente. Essa prática é utilizada para a experimentação de outras convergentes com os interesses e necessidades dos participantes e ajustadas aos propósitos do planejamento do grupo ou comunidade envolvida (RUAS et al., 2006).

Essas unidades foram implantadas no período chuvoso de outubro de 2010 e março de 2011, com acompanhamento técnico da EMATER-MG, sendo que cada uma recebeu material e orientação técnica para a instalação de dois hectares de ILPF. Nas áreas de recuperação de pastagens, o milho para silagem foi implantado em conjunto com o Brachiária Brizantha $C V$. BRS Piatã, visando a implantação de piquetes para pastagem depois de colhida a silagem.

A área selecionada para a ILPF foi a de pastagem mais degradada na propriedade ou usada recorrentemente para plantio de milho silagem. Essa área de lavoura foi circundada com 500 plantas de eucalipto em duas ou três fileiras no espaçamento $3 \mathrm{~m}$ x 3m. As primeiras adubações de cobertura com base em nitrogênio foram fornecidas pelo projeto até a realização do dia de campo.

Durante o primeiro ciclo de produção, após a colheita do milho para silagem, foram realizados quatro dias de campo nas UE dos municípios de Fortaleza de Minas, Alterosa, São João da Mata e Carmo do Rio Claro com o objetivo de apresentar e discutir os resultados obtidos com produtores e técnicos. A dinâmica das apresentações foi feita com o uso de três estações com demonstrações apresentando: Histórico de implantação da UE (com participação do extensionista local e produtor); Custos e estimativas de retorno econômico; Conceitos e fundamentos da ILPF (manejo dos sistemas); Adubação dos sistemas de ILPF (mineral e orgânica); Manejo das plantas (cultura e plantas daninhas) e pragas no sistema ILPF; e Mercado de produtos florestais.

\section{RESULTADOS E DISCUSSÃO}

As UE foram implantadas nos 12 municípios conforme previsto inicialmente no projeto e seguindo as orientações técnicas e modelos previstos inicialmente. A implantação das lavouras proporcionou uma adequada formação da forrageira que após a ensilagem do milho se estabeleceu plenamente entre 35 e 45 dias. Nesse período foi feita a divisão dos piquetes com sua área de lazer, onde havia saleiro, sombra e água. 
Esses piquetes proporcionaram uma maior taxa de lotação animal por área (UA/ha) e uma melhor qualidade das forragens ofertadas e menor custo de concentrados para complementar a dieta dos animais. Os animais entravam no Braquiaria Brizantha cv. Piatã quando estivessem com $45 \mathrm{~cm}$ de altura e saíam com $25 \mathrm{~cm}$ de resíduo. Esse manejo de altura de entrada e saída dos animais também contribuiu para melhor eficiência do sistema.

Em duas localidades os proprietários decidiram aumentar a área de piquetes fazendo para isso um investimento próprio, o que demonstra uma boa aceitação da proposta. No município de São João da Mata, houve elevação da produção dos animais assim que eles entraram nos piquetes.

As áreas de proteção foram cercadas e reflorestadas com espécies nativas e que permitirão seu aproveitamento econômico de acordo com a legislação vigente (Figura 1).

O isolamento das APP com nascentes, impedindo o acesso e pisoteio pelos animais, proporcionou uma recuperação e melhoria da qualidade e quantidade da água disponível. Nos municípios de Boa Esperança e Carmo do Rio Claro houve relato dos produtores de acréscimo na vazão das nascentes, mesmo em períodos de estiagem.

Figura 1 - (A) Nascente protegida por cerca e reflorestada com espécies nativas em Fortaleza de Minas-MG; (B) área de piquetes em São João da Mata-MG; (C) mudas de eucalipto para o sistema ILPF em Alterosa-MG.

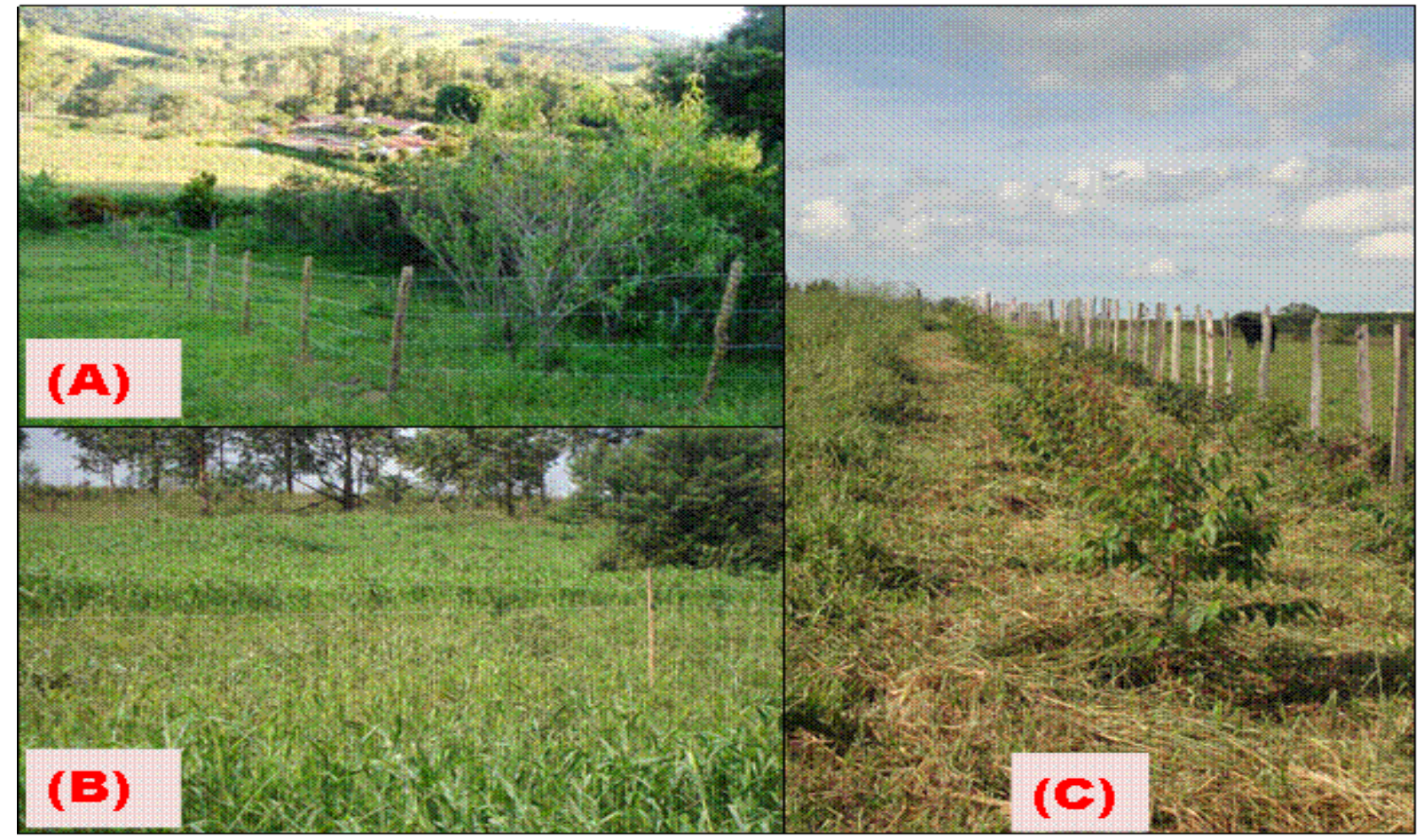

Fonte: Os autores (2019). 
Foram realizados quatro dias de campo, nos municípios de Alterosa, Carmo do Rio Claro, Fortaleza de Minas e São João da Mata, com a participação de 138 produtores rurais. Como previsto inicialmente, as estações abordaram o histórico da propriedade e de implantação da UE, com participação do extensionista local e produtor, custos e estimativas de retorno econômico, conceitos e fundamentos da ILPF e adubação dos sistemas de ILPF. A discussão com base em dados da propriedade local, que representa uma realidade vivida pelos produtores participantes do dia de campo, trouxe grande motivação para os produtores e técnicos presentes. Assim, foi possível perceber claramente que esse modelo de dias de campo permitiu maior interação dos agricultores e técnicos do município e vizinhos, tanto da EMATER-MG, quanto de cooperativas e autônomas com os temas essenciais ao êxito na atividade (Figura 2).

Figura 2 - Dias de campo em Fortaleza de Minas-MG (A) e Alterosa-MG (B)

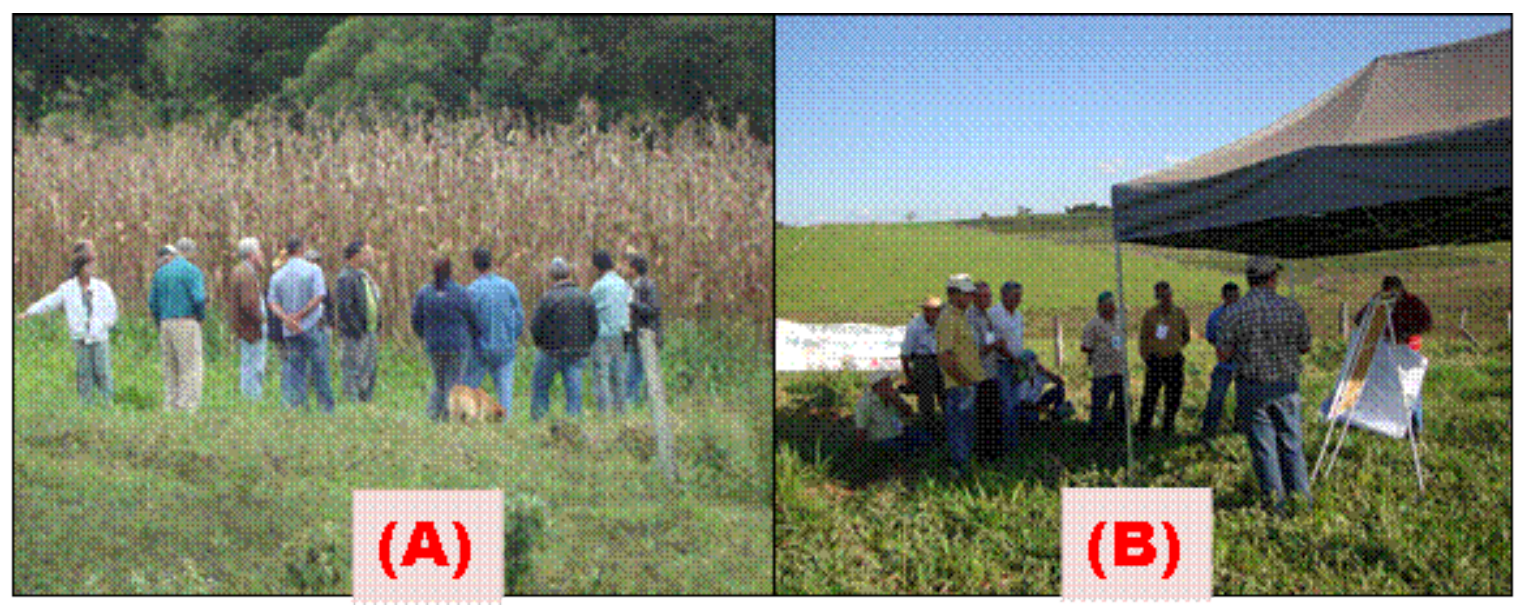

Fonte: Os autores (2019).

\section{CONSIDERAÇÕES FINAIS}

Os sistemas de ILPF se mostraram alternativas viáveis para a geração de renda nas propriedades familiares, respeitando-se as exigências impostas pela legislação ambiental. Dessa forma, favorece-se o produtor rural e a sociedade como um todo, que se beneficia da preservação do meio ambiente. Tal estratégia permitirá ainda a capacitação para implantação de novas áreas e programas, como o de Fomento Florestal, que poderão proporcionar a implantação das outras áreas de plantio, viabilizando o incremento de maior número de propriedades no sistema ILPF. 
Dessa forma, o projeto possibilitou uma efetiva transferência de tecnologia e conhecimento entre a comunidade atendida, acadêmicos, docentes e EMATER-MG.

\section{REFERÊNCIAS}

ALMG - ASSEMBLEIA LEGISLATIVA DE MINAS GERAIS. Lei Estadual $n^{\circ} 18.365$, de $1^{\circ}$ de novembro de 2009. Disponível em:

http://www.almg.gov.br/index.asp?grupo=legislacao\&diretorio=njmg\&arquivo=legislacao_m ineira. Acesso em: 16 mar. 2019.

BACHA, C. J. C. Eficácia da política de reserva ambiental no Brasil. Teoria e evidência econômica, São Paulo, v. 13, n. 25, p. 9-27, 2005.

BRASIL. Lei $n^{\circ} 12.651$, de 25 de maio de 2012. Dispõe sobre a proteção da vegetação nativa; altera as Leis $\mathrm{n}^{\text {os }} 6.938$, de 31 de agosto de 1981; 9.393, de 19 de dezembro de 1996; e 1.428, de 22 de dezembro de 2006; revoga as Leis $\mathrm{n}^{\text {os }} 4.771$, de 15 de setembro de 1965, e 7.754, de 14 de abril de 1989, e a Medida Provisória n 2.166-67, de 24 de agosto de 2001; e dá outras providências. Diário Oficial da União, Brasília, DF, 28 maio 2012.

FERREIRA, J. M. et al. Gestão ambiental: o papel protagonista do produtor rural. Informe Agropecuário, Belo Horizonte, p. 26-38, 2014.

IBGE - INSTITUTO BRASILEIRO DE GEOGRAFIA E ESTATÍSTICA. Sistema de Contas Nacionais Trimestrais-SCNT. Disponível em: https://www.ibge.gov.br/estatisticas/economicas/contas-nacionais/9300-contas-nacionaistrimestrais.html?edicao=20920\&t=series-historicas. Acesso em: 10 set. 2019.

MINAS GERAIS. Código Florestal de Minas Gerais. Lei $\mathrm{n}^{\circ}$ 20.922, de 16 de outubro de 2013. Dispõe sobre a política florestal e de proteção à biodiversidade no Estado. Minas Gerais, Belo Horizonte, 17 out. 2013. p. 1.

PADOVAN, M. P.; PEZARICO, C. R.; OTSUBO, A. A. Tecnologias para a agricultura familiar. 2. ed. Dourados, MS: EMBRAPA Agropecuária Oeste, 2015.

RUAS, E. D. et al. Metodologia participativa de extensão rural para o desenvolvimento sustentável. Belo Horizonte: MEXPAR, 2006.

SEIDEL, R. V.; FOLETO, E. M. A efetivação da legislação ambiental pertinente às propriedades rurais: algumas alternativas frente ao contexto atual. Geografia: Ensino \& Pesquisa, Santa Maria, v. 13, n. 2, p. 320-325, 2009.

Submetido em 10 de outubro de 2019.

Aprovado em 11 de novembro de 2019. 